\title{
Magnetic Interactions in Iron(III) Porphyrin Chlorides
}

\author{
Josef Ernst, Japyesan Subramanian *, and Jürgen-Hinrich Fuhrhop * \\ Gesellschaft für Biotechnologische Forschung mbH, \\ Mascheroder Weg 1, D-3300 Braunschweig-Stöckheim, W.-Germany \\ (Z. Naturforsch. 32 a, 1129-1136 [1977] ; received July 21, 1977) \\ * Dept. of Chemistry, North Eastern Hill University, Bijni House, Shillong 793003, India \\ ** Institut für Organische Chemie A der Technischen Universität Braunschweig, \\ Schleiniststr., D-3300 Braunschweig, W.-Germany
}

\begin{abstract}
Intermolecular exchange interactions in iron(III) porphyrin chlorides (porphyrin $=$ OEP, proto, TPP) have been studied by x-ray structure, EPR and magnetic susceptibility studies.

The crystal structure of $\mathrm{Fe}$ (III) OEP-Cl was found to be different from that of the other two. Different types of exchange broadened EPR-spectra are obtained which are attributable to the arrangement in the crystals. The EPR results correlate well with magnetic susceptibilty data.
\end{abstract}

\section{Introduction}

Iron(III) porphyrins in solutions exist either in the high-spin $(S=5 / 2)$ or low spin $(S=1 / 2)$ state with characteristic EPR-spectra ${ }^{1-4}$. In the high spin state one normally observes for a frozen solution two transitions $\left(g_{\perp}=6.0, g_{\|}=2.0\right)$ arising due to the very large axial zero field splitting $(D=10$ $\mathrm{cm}^{-1}$ ). Heme proteins with high spin iron(III) also exibit similar EPR characteristics, though in some cases, the $g=6$ line is split indicating small rhombicity. In the low-spin state $(\mathrm{S}=1 / 2)$ one observes axial or rhombic $g$-tensors. Intermediate $(S=3 / 2)$ spin states have also been characterized in some proteins containing iron(III) porphyrins. In the present paper we report the EPR-spectra of some iron(III) porphyrins in the polycrystalline state at liquid nitrogen and liquid helium temperatures. These spectra do not fall into anyone of the three groups described above.

We have found that the EPR data are explainable only in terms of intermolecular magnetic exchange interactions. Various solid state EPR spectra will therefore be correlated with crystal structure data. In adition, susceptibility measurements at different temperatures were also performed to characterize the systems.

\section{Experimental}

\section{A) Materials}

The iron(III) chloride complexes of octaethylporphyrin (OEP), protoporphyrin (proto) and tetraphenylporphyrin (TPP) were obtained by the usual crystallization of the iron(III) porphyrins from

Reprint requests to Dr. J. H. Fuhrhop, GBF - Mascheroder Weg 1, D-3300 Braunschweig-Stöckheim. acetic-acid in the presence of sodium chloride ${ }^{5}$. The acetate of $\mathrm{Fe}$ (III) (OEP) was prepared from the $\mu$-oxo-dimer by crystallization in acetic acid.

\section{B) EPR-Measurements}

EPR spectra were recorded using a Bruker BER 414S spectrometer operating at X-band with $100 \mathrm{kHz}$ field modulation. Measurements at liquidnitrogen-temperature were made by the gas flow technique, whereas a cold finger liquid helium insert dewar (Scanlan, U.S.A.) was used for liquid helium temperatures. Microwave power was kept as low as possible in the latter case.

\section{C) X-ray Study of Iron(III) (OEP)Cl}

Good crystals of $\mathrm{Fe}$ (III) (OEP) $\mathrm{Cl}$ were obtained by vapor diffusion of diethylether into a concentrated solution of $\mathrm{Fe}$ (III) (OEP) $\mathrm{Cl}$ in chloroform within one week. A crystal with dimensions of $0.25 \times 0.25$ $\times 0.08 \mathrm{~mm}$ was mounted in such a way that the $c$-axis was parallel to the goniometer axis. The intensity data were collected in the $\Theta=2 \Theta$ mode $\left(3.0 \leqq 2 \Theta \leqq 46.0^{\circ}\right)$ on a Syntex $\mathrm{P} 2{ }_{1}$ four-circle diffractometer with graphite monochromated $\mathrm{MoK}_{a}$ radiation.

Scan speeds varied between 2.93 and $9.77^{\circ} \mathrm{min}^{-1}$ with equal scan and background times. Of the 8824 reflections (one half of the reciprocal space) recorded, 2635 were considered to be observed as independent reflections with $F>4.0$ (F) (internal consistency index $=R=0.026$ ). The intensities were reduced for Lorentz and polarisation corrections.

Three standard reflections showed no significant alterations, during data collection.

Crystal D a t a:

$\mathrm{C}_{36} \mathrm{H}_{44} \mathrm{~N}_{4} \mathrm{FeCl}, M=624.1$. Systematic absences h0l $(\mathrm{l}=2 n), 0 \mathrm{k} 0 \quad(\mathrm{k}=2 n)$ confirm the space groups $\mathrm{P} 21 / \mathrm{c}$ (Nr. 14) monoclin, $Z=4$. 
Cell dimensions $(\AA): \quad a=15.715(8), \quad b=$ $22.424(14), c=10.109(6), \beta=112.40(5)^{\circ}, V=$ $3293.4(2.4) \AA^{3}, D_{\text {cal }}=1.26 \mathrm{gcm}^{-3}, \mathrm{Mo}_{\mathrm{\alpha}}-\mathrm{K}_{\mathrm{a}}$-radiation $\lambda=0.71069 \AA, \mu=3.56 \mathrm{~cm}^{-1}$.

Structure Solution and Refinement

The structure was solved by use of an automatic centrosymmetric direct method where $2^{14}$ phase permutations were expanded on the basis of the equation: $s(h)=s(\Sigma E(k) \cdot E(h-k))^{6}$. An M(abs)test was used to reject permutation, if their internal consistency fell below a specified value. A similarity test was applied to avoid the calculation of too many closely similar $E$ maps. The only calculated $E$ map showed 18 of the 42 heavy atom positions. The remainder were obtained from differenceFourier syntheses. Complex neutral atom scattering factors were employed ${ }^{7,8}$. The parameters were first refined with isotropic and later with anisotropic temperature factor components by blocked fullmatrix least-squares-method, the function $\Sigma \omega \Delta^{2}$ being minimised.

A difference Fourier synthesis yielded the positions of the hydrogen atoms. They were included as parameter with isotropic temperature factors in the last cycles of refinement. The final value of the generalised index $R_{\mathrm{G}}=\left(\Sigma \omega \Delta^{2} / \Sigma \omega F_{0}\right)^{1 / 2}$ was 0.056 , the weighted residual $R_{\mathrm{w}}=\sum \omega^{1 / 2} \Delta / \Sigma \omega^{1 / 2} F_{0}$ was 0.054 and $R=0.073$. The weights used, were given by the expression $\omega=K /\left(\sigma^{2}\left(F_{0}\right)+g F_{0}\right)^{2}$, where $K$ refined to 1.07128 and $g$ to -0.000301 . In the last difference Fourier synthesis, maxima in electron density of $0.57 \mathrm{e}^{-3}$ were observed near the heaviest atoms $\mathrm{Fe}$ and $\mathrm{Cl}$. All other maxima were smaller than $0.41 \AA^{-3}$. 131 reflections showed differences between $F_{0}$ and $F_{\text {c }}$ greater than $2.0 \sigma\left(F_{\mathrm{c}}\right)$.

The final atom positions are listed in Table 1 . The bond lengths and bond angles with their standard deviations were calculated from these values by means of all-covariance-matrix and are listed in Table 2 and 3.

\section{D) Magnetic Susceptibility of $\mathrm{Fe}(\mathrm{III})(\mathrm{OEP}) \mathrm{Cl}$}

The susceptibility was measured by the Faradaymethod from 3.04 to $297 \mathrm{~K}$. $0.4 \mathrm{~g}$ of finely powdered $\mathrm{Fe}(\mathrm{III})(\mathrm{OEP}) \mathrm{Cl}$ were used. The sample was analyzed for possible ferromagnetic contaminations by susceptibility measurements in magnetic fields from 3 to $15 \mathrm{kG}$ at all temperatures. A constant value for the susceptibility within an experimental error of $\pm 2 \%$ was always found. This implies the absence of any ferromagnetic impurities in sufficient amounts to affect the results of the experiments. Diamagnetic corrections were made using the additivity rule [diamagnetic correction = $\left.-393 \cdot 10^{-6}\left(\mathrm{~cm}^{3} / \mathrm{mol}\right)\right]$.
Table 1. Positional parameters.

\begin{tabular}{llll}
\hline & $x / A$ & $y / B$ & $\mathrm{z} / \mathrm{C}$ \\
\hline $\mathrm{FE}$ & $0.2582(1)$ & $0.0447(1)$ & $0.5087(1)$ \\
$\mathrm{CL}$ & $0.2835(1)$ & $0.1003(1)$ & $0.3444(1)$ \\
$\mathrm{N}(21)$ & $0.2935(3)$ & $0.9592(2)$ & $0.4737(5)$ \\
$\mathrm{C}(1)$ & $0.3824(4)$ & $0.9365(3)$ & $0.5177(7)$ \\
$\mathrm{C}(2)$ & $0.3828(4)$ & $0.8801(3)$ & $0.4479(7)$ \\
$\mathrm{C}(3)$ & $0.2932(5)$ & $0.8685(3)$ & $0.3611(7)$ \\
$\mathrm{C}(4)$ & $0.2390(4)$ & $0.9173(2)$ & $0.3779(7)$ \\
$\mathrm{C}(5)$ & $0.1437(5)$ & $0.9237(3)$ & $0.3079(7)$ \\
$\mathrm{N}(22)$ & $0.1221(3)$ & $0.0180(2)$ & $0.4112(5)$ \\
$\mathrm{C}(6)$ & $0.0904(4)$ & $0.9698(3)$ & $0.3226(7)$ \\
$\mathrm{C}(7)$ & $0.9904(4)$ & $0.9726(3)$ & $0.2488(7)$ \\
$\mathrm{C}(8)$ & $0.9641(4)$ & $0.0235(3)$ & $0.2939(7)$ \\
$\mathrm{C}(9)$ & $0.0459(4)$ & $0.0528(3)$ & $0.3969(7)$ \\
$\mathrm{C}(10)$ & $0.0474(4)$ & $0.1034(3)$ & $0.4713(7)$ \\
$\mathrm{N}(23)$ & $0.2125(3)$ & $0.1074(2)$ & $0.6147(5)$ \\
$\mathrm{C}(11)$ & $0.1235(4)$ & $0.1293(3)$ & $0.5729(7)$ \\
$\mathrm{C}(12)$ & $0.1221(4)$ & $0.1811(3)$ & $0.6579(7)$ \\
$\mathrm{C}(13)$ & $0.2096(4)$ & $0.1907(2)$ & $0.7508(7)$ \\
$\mathrm{C}(14)$ & $0.2658(4)$ & $0.1453(3)$ & $0.7221(7)$ \\
$\mathrm{C}(15)$ & $0.3611(5)$ & $0.1408(3)$ & $0.7888(7)$ \\
$\mathrm{N}(24)$ & $0.3842(3)$ & $0.0497(2)$ & $0.6761(5)$ \\
$\mathrm{C}(16)$ & $0.4169(4)$ & $0.0970(3)$ & $0.7701(7)$ \\
$\mathrm{C}(17)$ & $0.5163(4)$ & $0.0922(3)$ & $0.8452(6)$ \\
$\mathrm{C}(18)$ & $0.5431(4)$ & $0.0424(3)$ & $0.7948(6)$ \\
$\mathrm{C}(19)$ & $0.4605(4)$ & $0.0162(3)$ & $0.6882(6)$ \\
$\mathrm{C}(20)$ & $0.4592(4)$ & $0.9645(3)$ & $0.6148(7)$ \\
$\mathrm{C}(21)$ & $0.4662(5)$ & $0.8433(4)$ & $0.4722(10)$ \\
$\mathrm{C}(22)$ & $0.4956(7)$ & $0.8072(4)$ & $0.6091(14)$ \\
$\mathrm{C}(31)$ & $0.2554(6)$ & $0.8148(4)$ & $0.2669(10)$ \\
$\mathrm{C}(32)$ & $0.2257(8)$ & $0.7670(5)$ & $0.3451(16)$ \\
$\mathrm{C}(71)$ & $0.9302(5)$ & $0.9278(3)$ & $0.1426(9)$ \\
$\mathrm{C}(72)$ & $0.9187(6)$ & $0.9401(4)$ & $0.9899(10)$ \\
$\mathrm{C}(81)$ & $0.8687(5)$ & $0.0494(4)$ & $0.2509(9)$ \\
$\mathrm{C}(82)$ & $0.8526(7)$ & $0.0986(5)$ & $0.1399(12)$ \\
$\mathrm{C}(121)$ & $0.0373(5)$ & $0.2168(3)$ & $0.6415(9)$ \\
$\mathrm{C}(122)$ & $0.0098(8)$ & $0.2610(6)$ & $0.5240(17)$ \\
$\mathrm{C}(131)$ & $0.2459(5)$ & $0.2366(3)$ & $0.8652(9)$ \\
$\mathrm{C}(132)$ & $0.2735(7)$ & $0.2124(4)$ & $1.0163(12)$ \\
$\mathrm{C}(171)$ & $0.5748(4)$ & $0.1359(3)$ & $0.9537(9)$ \\
$\mathrm{C}(172)$ & $0.5878(7)$ & $0.1197(6)$ & $1.1035(13)$ \\
$\mathrm{C}(181)$ & $0.6394(4)$ & $0.0168(3)$ & $0.8442(8)$ \\
$\mathrm{C}(182)$ & $0.6548(6)$ & $0.9667(3)$ & $0.9518(9)$ \\
\hline & & &
\end{tabular}

\section{Results}

\section{A) EPR Spectra}

The EPR-spectrum of polycrystalline $\mathrm{Fe}$ (III) (OEP) $\mathrm{Cl}$ at $80^{\circ} \mathrm{K}$ is quite different from that of a frozen solution at the same temperature. There is a strong transition (linewidth $=560$ Gauss) around $g=3.5$ and a weak line at $g>6$. No lines are observed in the $g=2$ region. At liquid helium temperature the lines sharpen and transitions are observed at $g=10.4,5.8,3.6$ and 3.2 (linewidths: $125 ; 100 ; 280 ; 250 \mathrm{G})$. The relative intensities and widths of the lines are strongly dependent on the nature of the counterion $\left(\mathrm{Cl}^{-}\right.$or acetate $)$as well as the porphyrin ligand. With $\mathrm{Fe}$ (III) (OEP) 
Table 2. Bond lengths $(\AA)$.

\begin{tabular}{|c|c|c|c|c|c|}
\hline CL & $-\mathrm{FE}$ & $2.231(2)$ & $\mathrm{N}(21)$ & $-F E$ & $2.063(6)$ \\
\hline $\mathrm{N}(22)$ & $-F E$ & $2.073(5)$ & $\mathrm{N}(23)$ & $-F E$ & $56(6)$ \\
\hline N (24) & $-\mathrm{FE}$ & $2.060(4)$ & $\mathrm{C}(1)$ & $-\mathrm{N}(21)$ & $1.391(9)$ \\
\hline C (4) & $-\mathrm{N}(21)$ & $1.387(8)$ & (2) & $-\mathrm{C}(1)$ & $1.449(10)$ \\
\hline C (20) & $-\mathrm{C}(1)$ & 9) & (3) & $-\mathrm{C}(2)$ & $1.370(9)$ \\
\hline $\mathrm{C}(21)$ & $-\mathrm{C}(2)$ & $8(11)$ & 4) & $-\mathrm{C}(3)$ & $1.436(11)$ \\
\hline C (31) & $-\mathrm{C}(3)$ & $1.510(11)$ & C (5) & $-C(4)$ & $1.399(10)$ \\
\hline $\mathrm{C}(6)$ & $-C(5)$ & $1.374(11)$ & $\mathrm{C}(6)$ & $-\mathrm{N}(22)$ & $1.372(9)$ \\
\hline C (9) & $-\mathrm{N}(22)$ & $1.389(9)$ & C (7) & $-C(6)$ & $1.462(9)$ \\
\hline C (8) & $-\mathrm{C}(7)$ & $1.349(11)$ & $C(71)$ & $-C(7)$ & $1.511(10)$ \\
\hline$C(9)$ & $-C(8)$ & 1.465 (9) & $\mathrm{C}(81)$ & $-C(8)$ & 1.509 (11) \\
\hline (10) & $-\mathrm{C}(9)$ & 1.3 & $\mathrm{C}(11)$ & $-C(10)$ & 1.374 \\
\hline (11) & $-\mathrm{N}(23)$ & $8(9)$ & 4) & $-\mathrm{N}(23)$ & $1.381(8)$ \\
\hline C (12) & $-\mathrm{C}(11)$ & 11) & $\mathrm{C}(13)$ & 2) & (9) \\
\hline 4 & $-\mathrm{C}$ & & & $-\mathrm{C}$ & (11) \\
\hline ) & $-\mathrm{C}($ & 1.4 & Ci & $-\mathrm{C}($ & $2(10)$ \\
\hline $\mathrm{C}(16)$ & $-\mathrm{C}(15)$ & (11) & $C(16)$ & $-\mathrm{N}(24)$ & 1.385 (9) \\
\hline C (19) & $-\mathrm{N}(24)$ & $1.381(9)$ & $\mathrm{C}(17)$ & $-C(16)$ & $1.457(9)$ \\
\hline C (18) & $-\mathrm{C}(17)$ & 1.359 (11) & $\mathrm{C}(171)$ & $-\mathrm{C}(17)$ & $1.497(10)$ \\
\hline $\mathrm{C}(19)$ & $-C(18)$ & $1.458(8)$ & $C(18$ & $-\mathrm{C}(18)$ & $1.515(10)$ \\
\hline $\mathrm{C}(20)$ & $-\mathrm{C}(19)$ & $1.371(10)$ & $\mathrm{C}(22)$ & $-C(21)$ & $1.517(16)$ \\
\hline $\mathrm{C}(32)$ & $-\mathrm{C}(31)$ & $1.506(19)$ & $\mathrm{C}(72)$ & $-C(71)$ & $1.509(14)$ \\
\hline C (82) & $-C(81)$ & $1.525(15)$ & $\mathrm{C}(122)$ & $-\mathrm{C}(121)$ & $1.480(18)$ \\
\hline C (132) & $-\mathrm{C}(131)$ & $1.520(14)$ & $\mathrm{C}(172)$ & $-\mathrm{C}(171)$ & $1.493(17)$ \\
\hline$C(182)$ & $-\mathrm{C}(181)$ & $1.517(12)$ & & & \\
\hline
\end{tabular}

OAc the $g=5.3$ line is strong and a relatively weak absorption is seen at $g=3.0$ (linewidths $=430 \mathrm{G}$ ) at $80 \mathrm{~K}$. With $\mathrm{Fe}(\mathrm{III})$ (Proto) $\mathrm{Cl}$ a broad line is seen at $g=6.4$ (linewidths $=560 \mathrm{G}$ ) at $80 \mathrm{~K}$ and this line is split at liquid helium temperature into two lines with absorption lineshape at $g=2.5$ and 3.5 (linewidths $=500 \mathrm{G}$ ). Quite different types of spectra are noticed for $\mathrm{Fe}$ (III) (TPP) Cl. At $80 \mathrm{~K}$ sharp $g=5.6, g=2.5$ and $g=2.0$ lines are observed (linewidths: $270 \mathrm{G})$. At liquid helium temperature the lines appeared at $g=6.1, g=4.1$ and $g=2.0$. The lines (linewidths $=30 \mathrm{G}$ ) are quite sharp compared to $\mathrm{Fe}(\mathrm{III})(\mathrm{OEP}) \mathrm{Cl}$ and $\mathrm{Fe}(\mathrm{III})$ (proto) $\mathrm{Cl}$. The EPR-spectra at $4.2 \mathrm{~K}$ are shown in Figure 1. In order to know whether the intermolecular iron-iron interactions contribute to the EPR spectra, a dilution experiment was performed with $\mathrm{Fe}$ (III) (OEP) Cl. The $\mathrm{Fe}$ (III) complex was mixed with the free base OEP in a molar ratio of $1: 2$, dissolved in chloroform and the solution was evaporated very slowly. The EPR spectra of polycrystalline material thus obtained indicated relatively sharp $g=6$ and $g=2$ lines and a broad, weak line at $g=3.5$. It appeared that not all of the $\mathrm{Fe}$ (III) $(\mathrm{OEP}) \mathrm{Cl}$ had gone into the lattice of the free base. A small part of it had probably coprecipated which gave rise to the broad line at $g=3.5$. The rest of the $\mathrm{Fe}$ (III) $(\mathrm{OEP}) \mathrm{Cl}$ which had been doped into the lattice of the free

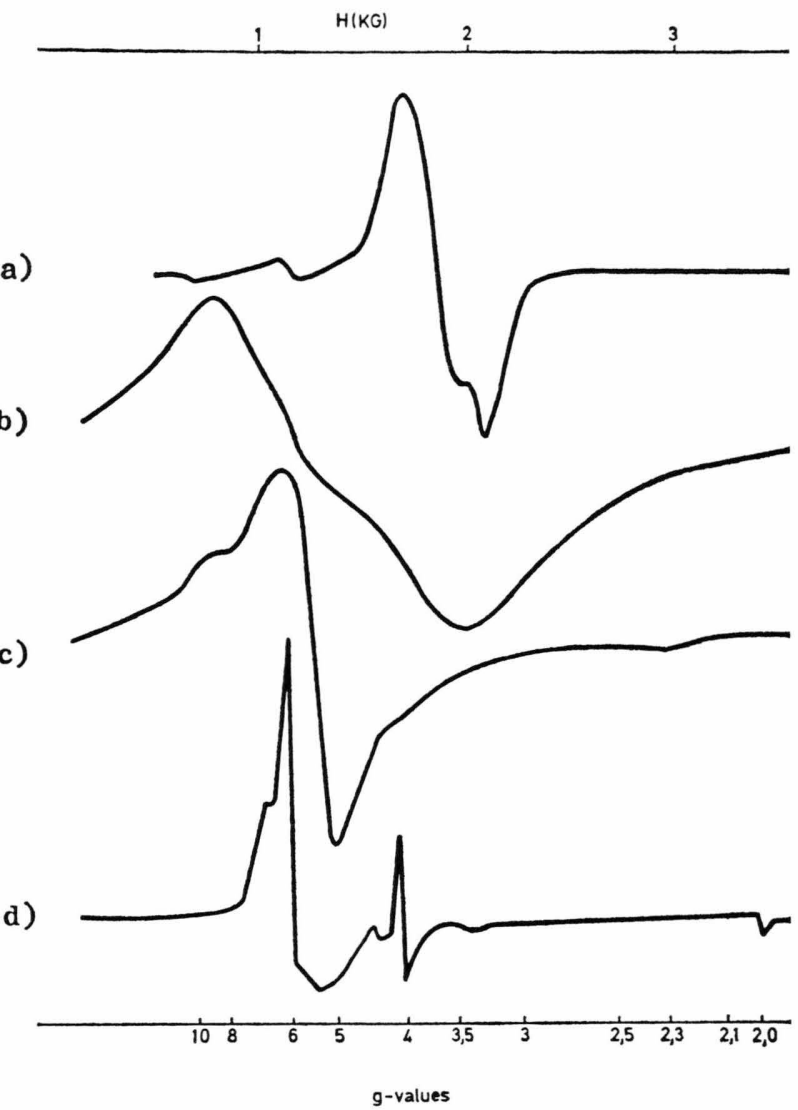

Fig. 1. EPR spectra of a) $\mathrm{Fe}(\mathrm{III})(\mathrm{OEP}) \mathrm{Cl}$, b) $\mathrm{Fe}(\mathrm{III})$ (proto) $\mathrm{Cl}$, c) $\mathrm{Fe}$ (III) (OEP) OAc, and d) $\mathrm{Fe}$ (III) (TPP) $\mathrm{Cl}$ at $4.2 \mathrm{~K}$.

base OEP gave rise to $g=6$ and $g=2$ lines, thus demonstrating that the $g=3.5$ line arise from intermolecular spin-spin interactions.

\section{B) Crystal Structure}

Details of the molecular and crystal structures of $\mathrm{Fe}$ (III) (OEP) $\mathrm{Cl}$ are given in Figures 2 and 3. The crystal data of the three iron(III) chloride porphyrin complexes investigated by EPR-spectroscopy are given in Table 5. Data for $\mathrm{Fe}$ (III) (proto) $\mathrm{Cl}$ and $\mathrm{Fe}$ (III) (TPP) $\mathrm{Cl}$ have been taken from the literature ${ }^{9,10}$, the analysis of $\mathrm{Fe}(\mathrm{III})(\mathrm{OEP}) \mathrm{Cl}$ is described in the experimental section.

The molecular environment around the $\mathrm{Fe}$ (III)ions in all these cases is nearly identical: the porphyrin ring is slightly bent (deviations from the N-plane $\leqq 0.2 \AA$ ) and the iron is roughly $0.5 \AA$ out of plane. Average bond lengths of chemically equivalent bonds are given in Table 4 . 
Table 3. Bond angles.

\begin{tabular}{|c|c|c|c|c|c|c|c|}
\hline $\mathrm{N}(21)$ & $-\mathrm{FE}$ & $-\mathrm{CL}$ & $104.8(2)$ & $\mathrm{N}(22)$ & $-\mathrm{FE}$ & $-\mathrm{CL}$ & $104.6(2)$ \\
\hline $\mathrm{N}(22)$ & $-\mathrm{FE}$ & $-\mathrm{N}(21)$ & $86.9(2)$ & $\mathrm{N}(23)$ & $-\mathrm{FE}$ & $-\mathrm{CL}$ & $101.7(2)$ \\
\hline$N(23)$ & $-\mathrm{FE}$ & $-N(21)$ & $153.5(2)$ & $N(23)$ & $-\mathrm{FE}$ & $-\mathrm{N}(22)$ & $86.8(2)$ \\
\hline $\mathrm{N}(24)$ & $-\mathrm{FE}$ & $-\mathrm{CL}$ & $101.1(2)$ & $\mathrm{N}(24)$ & $-\mathrm{FE}$ & $-\mathrm{N}(21)$ & $87.4(2)$ \\
\hline$N(24)$ & $-F E$ & $-\mathrm{N}(22)$ & $154.3(2)$ & $N(24)$ & $-\mathrm{FE}$ & $-\mathrm{N}(23)$ & $87.2(2)$ \\
\hline $\mathrm{C}(1)$ & $-\mathrm{N}(21)$ & $-\mathrm{FE}$ & $126.0(4)$ & $\mathrm{C}(4)$ & $-\mathrm{N}(21)$ & $-\mathrm{FE}$ & $128.0(4)$ \\
\hline C (4) & $-\mathrm{N}(21)$ & $-\mathrm{C}(1)$ & $104.6(6)$ & C (2) & $-\mathrm{C}(1)$ & $-\mathrm{N}(21)$ & $110.7(5)$ \\
\hline C (20) & $-\mathrm{C}(1)$ & $-\mathrm{N}(21)$ & $124.0(7)$ & $\mathrm{C}(20)$ & $-\mathrm{C}(1)$ & $-\mathrm{C}(2)$ & $125.3(7)$ \\
\hline $\mathrm{C}(3)$ & $-\mathrm{C}(2)$ & $-\mathrm{C}(1)$ & $106.5(6)$ & $\mathrm{C}(21)$ & $-\mathrm{C}(2)$ & $-\mathrm{C}(1)$ & 124.8 (6) \\
\hline $\mathrm{C}(21)$ & $-\mathrm{C}(2)$ & $-\mathrm{C}(3)$ & $128.7(7)$ & $C(4)$ & $-\mathrm{C}(3)$ & $-\mathrm{C}(2)$ & $106.9(6)$ \\
\hline C (31) & $-\mathrm{C}(3)$ & $-\mathrm{C}(2)$ & $128.1(7)$ & $\mathrm{C}(31)$ & $-\mathrm{C}(3)$ & $-C(4)$ & $125.0(6)$ \\
\hline C (3) & $-C(4)$ & $-\mathrm{N}(21)$ & $111.3(6)$ & $\mathrm{C}(5)$ & $-\mathrm{C}(4)$ & $-\mathrm{N}(21)$ & $122.7(7)$ \\
\hline C (5) & $-\mathrm{C}(4)$ & $-\mathrm{C}(3)$ & $126.0(6)$ & $\mathrm{C}(6)$ & $-\mathrm{C}(5)$ & $-\mathrm{C}(4)$ & $127.0(6)$ \\
\hline$C(6)$ & $-\mathrm{N}(22)$ & $-\mathrm{FE}$ & $126.1(5)$ & C (9) & $-\mathrm{N}(22)$ & $-\mathrm{FE}$ & $125.5(4)$ \\
\hline C (9) & $-\mathrm{N}(22)$ & $-\mathrm{C}(6)$ & $106.9(5)$ & $\mathrm{N}(22)$ & $-\mathrm{C}(6)$ & $-\mathrm{C}(5)$ & $125.5(6)$ \\
\hline C (7) & $-\mathrm{C}(6)$ & $-\mathrm{C}(5)$ & $124.0(6)$ & $\mathrm{C}(7)$ & $-\mathrm{C}(6)$ & $-\mathrm{N}(22)$ & $110.5(6)$ \\
\hline $\mathrm{C}(8)$ & $-\mathrm{C}(7)$ & $-\mathrm{C}(6)$ & $105.8(6)$ & $\mathrm{C}(71)$ & $-\mathrm{C}(7)$ & $-\mathrm{C}(6)$ & $126.4(7)$ \\
\hline C (71) & $-\mathrm{C}(7)$ & $-\mathrm{C}(8)$ & $127.8(6)$ & $\mathrm{C}(9)$ & $-\mathrm{C}(8)$ & $-\mathrm{C}(7)$ & $108.7(6)$ \\
\hline $\mathrm{C}(81)$ & $-\mathrm{C}(8)$ & $-\mathrm{C}(7)$ & $128.7(6)$ & $\mathrm{C}(81)$ & $-\mathrm{C}(8)$ & $-\mathrm{C}(9)$ & $122.5(7)$ \\
\hline C (8) & $-\mathrm{C}(9)$ & $-\mathrm{N}(22)$ & $108.1(6)$ & $\mathrm{C}(10)$ & $-\mathrm{C}(9)$ & $-\mathrm{N}(22)$ & $125.4(6)$ \\
\hline C $(10)$ & $-\mathrm{C}(9)$ & $-\mathrm{C}(8)$ & $126.5(7)$ & $\mathrm{C}(11)$ & $-\mathrm{C}(10)$ & $-\mathrm{C}(9)$ & $126.5(7)$ \\
\hline $\mathrm{C}(11)$ & $-\mathrm{N}(23)$ & $-\mathrm{FE}$ & $126.5(4)$ & $\mathrm{C}(14)$ & $-\mathrm{N}(23)$ & $-\mathrm{FE}$ & $127.1(5)$ \\
\hline $\mathrm{C}(14)$ & $-\mathrm{N}(23)$ & $-\mathrm{C}(11)$ & $105.1(6)$ & $\mathrm{N}(23)$ & $-\mathrm{C}(11)$ & $-\mathrm{C}(10)$ & $124.6(7)$ \\
\hline $\mathrm{C}(12)$ & $-\mathrm{C}(11)$ & $-\mathrm{C}(10)$ & $125.2(7)$ & $\mathrm{C}(12)$ & $-\mathrm{C}(11)$ & $-\mathrm{N}(23)$ & $110.1(5)$ \\
\hline C (13) & $-\mathrm{C}(12)$ & -C(11) & $107.3(6)$ & $\mathrm{C}(121)$ & $-\mathrm{C}(12)$ & $-\mathrm{C}(11)$ & $124.9(6)$ \\
\hline $\mathrm{C}(121)$ & $-\mathrm{C}(12)$ & $-\mathrm{C}(13)$ & $127.8(7)$ & $\mathrm{C}(14)$ & - C(13) & $-\mathrm{C}(12)$ & $106.5(6)$ \\
\hline C (131) & $-\mathrm{C}(13)$ & $-\mathrm{C}(12)$ & $129.4(7)$ & C (131) & $-\mathrm{C}(13)$ & $-\mathrm{C}(14)$ & $124.0(6)$ \\
\hline $\mathrm{C}(13)$ & $-\mathrm{C}(14)$ & $-\mathrm{N}(23)$ & $110.9(6)$ & $\mathrm{C}(15)$ & $-\mathrm{C}(14)$ & $-\mathrm{N}(23)$ & $123.7(7)$ \\
\hline C (15) & $-\mathrm{C}(14)$ & $-\mathrm{C}(13)$ & $125.4(6)$ & $\mathrm{C}(16)$ & $-\mathrm{C}(15)$ & $-\mathrm{C}(14)$ & $127.5(6)$ \\
\hline C (16) & $-\mathrm{N}(24)$ & $-\mathrm{FE}$ & $126.5(4)$ & C(19) & $-\mathrm{N}(24)$ & $-\mathrm{FE}$ & $125.0(4)$ \\
\hline C (19) & $-\mathrm{N}(24)$ & $-\mathrm{C}(16)$ & $105.9(5)$ & $\mathrm{N}(24)$ & $-\mathrm{C}(16)$ & $-\mathrm{C}(15)$ & $123.4(6)$ \\
\hline $\mathrm{C}(17)$ & $-\mathrm{C}(16)$ & $-\mathrm{C}(15)$ & $126.4(6)$ & $\mathrm{C}(17)$ & $-\mathrm{C}(16)$ & $-\mathrm{N}(24)$ & $110.2(6)$ \\
\hline C (18) & $-\mathrm{C}(17)$ & $-\mathrm{C}(16)$ & $106.8(5)$ & $\mathrm{C}(171)$ & $-\mathrm{C}(17)$ & $-\mathrm{C}(16)$ & $124.8(7)$ \\
\hline$C(171)$ & -C(17) & - C(18) & 128.4(6) & C(19) & $-\mathrm{C}(18)$ & $-\mathrm{C}(17)$ & $107.1(6)$ \\
\hline C (181) & $-\mathrm{C}(18)$ & $-\mathrm{C}(17)$ & $127.0(6)$ & C (181) & $-\mathrm{C}(18)$ & - C(19) & $125.9(7)$ \\
\hline C (18) & $-\mathrm{C}(19)$ & $-\mathrm{N}(24)$ & $110.1(6)$ & $\mathrm{C}(20)$ & $-\mathrm{C}(19)$ & $-\mathrm{N}(24)$ & $125.4(6)$ \\
\hline $\mathrm{C}(20)$ & $-\mathrm{C}(19)$ & $-\mathrm{C}(18)$ & $124.5(6)$ & C (19) & $-\mathrm{C}(20)$ & $-\mathrm{C}(1)$ & $126.6(7)$ \\
\hline $\mathrm{C}(22)$ & $-\mathrm{C}(21)$ & $-\mathrm{C}(2)$ & $113.0(9)$ & $\mathrm{C}(32)$ & $-\mathrm{C}(31)$ & $-\mathrm{C}(3)$ & $111.3(9)$ \\
\hline $\mathrm{C}(72)$ & $-\mathrm{C}(71)$ & $-\mathrm{C}(7)$ & $113.8(7)$ & C (82) & $-\mathrm{C}(81)$ & $-\mathrm{C}(8)$ & $111.0(9)$ \\
\hline $\mathrm{C}(122)$ & $-\mathrm{C}(121)$ & $-\mathrm{C}(12)$ & $114.8(0)$ & $\mathrm{C}(132)$ & $-\mathrm{C}(131)$ & $-\mathrm{C}(13)$ & $114.3(7)$ \\
\hline $\mathrm{C}(172)$ & $-\mathrm{C}(171)$ & $-\mathrm{C}(17)$ & $113.1(8)$ & C (182) & $-\mathrm{C}(181)$ & $-\mathrm{C}(18)$ & $112.6(7)$ \\
\hline
\end{tabular}

Table 4. Averaged bondlengths of chemical equivalent bonds $(\AA)$.

\begin{tabular}{llll}
\hline & $\mathrm{Fe}(\mathrm{OEP}) \mathrm{Cl}$ & $\mathrm{Fe}(\mathrm{TPP}) \mathrm{Cl}$ & $\mathrm{Fe}$ (proto) $\mathrm{Cl}$ \\
\hline $\mathrm{Fe}-\mathrm{N}-$ Ebene & 0.463 & $0.383(6)$ & 0.475 \\
$\mathrm{Fe}-\mathrm{Cl}$ & $2.231(2)$ & $2.192(12)$ & $2.218(6)$ \\
$\mathrm{Fe}-\mathrm{N}$ & $2.063(4)$ & $2.049(9)$ & $2.062(10)$ \\
$\mathrm{C}-\mathrm{N}$ & $1.384(2)$ & $1.384(10)$ & $1.384(7)$ \\
$\mathrm{C}_{\mathrm{a}}-\mathrm{C}_{\mathrm{b}}$ & $1.453(3)$ & $1.446(17)$ & $1.449(4)$ \\
$\mathrm{C}_{\mathrm{b}}-\mathrm{C}_{\mathrm{b}}$ & $1.358(4)$ & $1.380(17)$ & $1.337(4)$ \\
$\mathrm{C}_{\mathrm{a}}-\mathrm{C}_{\mathrm{m}}$ & $1.378(5)$ & $1.399(16)$ & $1.378(7)$ \\
\hline
\end{tabular}

Significant differences, however, are found in the crystal structures. In $\mathrm{Fe}$ (III) (proto) $\mathrm{Cl}$ the macrocycles are closest to each other. There are twenty interatomic distances from any porphyrin ring to the others, which are shorter than $4 \AA$. The closest intermolecular approach of two carbon atoms is $3.39 \AA$. In $\mathrm{Fe}$ (III) (OEP) Cl only forteen interatomic distances fall below $4 \AA$ and the shortest distance is $3.54 \AA$. With $\mathrm{Fe}$ (III) (TPP) Cl large separations between porphyrin rings are observed. The shortest interatomic C-C distance is $5.06 \AA$. The chloride ions, however, are situated with equal probability on either side of the porphyrin plane. For fifty percent of the molecules in this disordered structure, the separation of the chloride ion radii is of the order of $1 \AA$. This should therefore allow orbital overlap and superexchange interactions between associated iron ions in these isolated pairs.

It is difficult to represent the complicated molecular arrangement in the crystal lattice in a two dimensional projection. A visualization of probable interaction pathways is given in Figures $4-6$. Only 


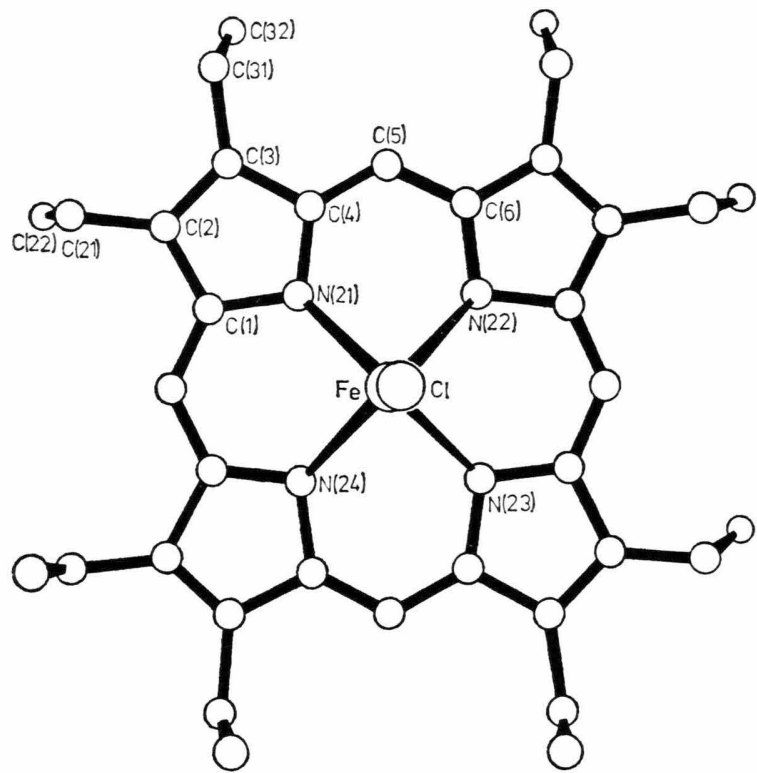

Fig. 2. Projection of $\mathrm{Fe}(\mathrm{III})(\mathrm{OEP}) \mathrm{Cl}$ onto the best plane of the nitrogen atoms. the periphery of the porphyrin rings together with shortest intermolecular $\mathrm{C}-\mathrm{C}, \mathrm{C}-\mathrm{Cl}$ and $\mathrm{C}-\mathrm{Fe}$ distances are given.

In $\mathrm{Fe}$ (III) (proto) $\mathrm{Cl}$ the nearest molecules from a chain along the $b$-axis. Figure 4 shows four molecules as seen from the $a$-axis. In the same manner in $\mathrm{Fe}(\mathrm{III})(\mathrm{OEP}) \mathrm{Cl}$ nearest interatomic distances occur along the $a$-axis. The chain is drawn in Fig. 5 as seen along the $b$-axis.

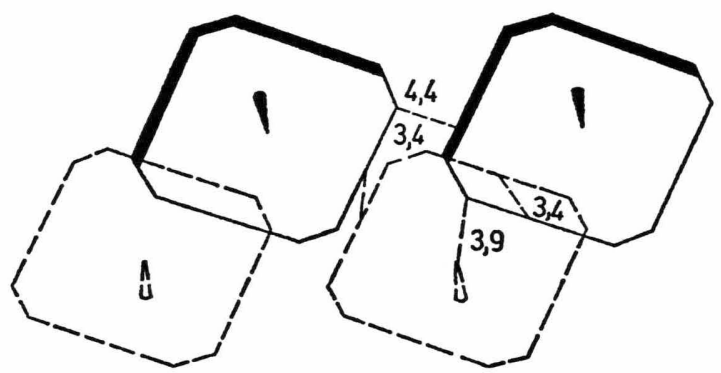

Fig. 4. Chain of nearest molecules of $\mathrm{Fe}$ (III) (proto) $\mathrm{Cl}$ along the $b$-axis as seen from the $a$-axis.

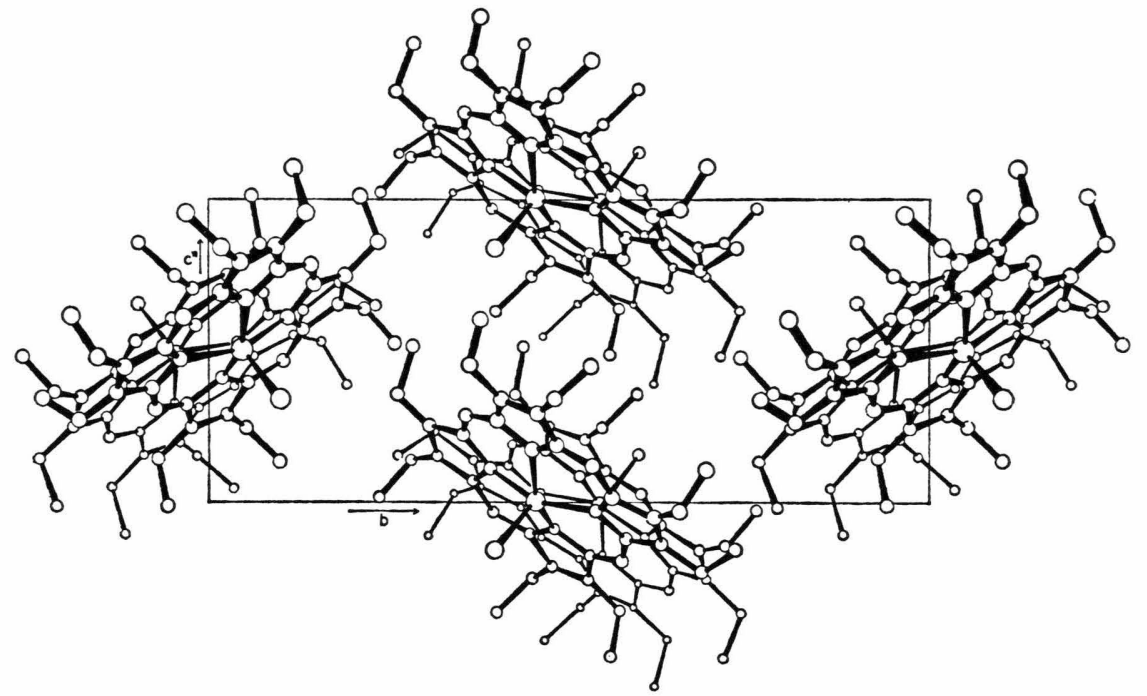

Fig. 3.

Projection of the unit-cell contents of $\mathrm{Fe}$ (III) (OEP) Cl onto a plane perpendicular to the $a$-axis.

Table 5. Crystal data of iron(III) porphyrinchlorids.

\begin{tabular}{|c|c|c|c|c|c|c|c|c|c|c|c|c|}
\hline Compound & $\begin{array}{l}\text { Space- } \\
\text { group }\end{array}$ & & $b$ & $c$ & $a$ & $\beta$ & $\gamma$ & $\begin{array}{l}\text { Intera } \\
\text { distan } \\
<5 \AA\end{array}$ & $\begin{array}{l}\text { omic } \\
<4 \AA\end{array}$ & $\begin{array}{l}\text { Smallest } \\
\text { interatomic } \\
\text { distance }\end{array}$ & $\begin{array}{l}\mathrm{Fe}-\mathrm{Fe} \\
<10 \AA\end{array}$ & Ref. \\
\hline $\mathrm{Fe}$ (III) (OEP) Cl & $\mathrm{P} 2_{1} / \mathrm{c}$ & 15.715 & 22.424 & 10.109 & 90 & 112.40 & 90 & 60 & 14 & 3.54 $\AA \mathrm{C}_{\mathrm{m}}-\mathrm{C}_{\mathrm{b}}$ & $\begin{array}{l}7.9 \\
8.3\end{array}$ & \\
\hline $\mathrm{Fe}$ (III) (Proto) $\mathrm{Cl}$ & $\mathrm{PI}$ & 11.494 & 14.097 & 10.854 & 98.56 & 108.49 & 107.65 & 104 & 20 & $3.39 \AA \mathrm{C}_{\mathrm{m}}-\mathrm{C}_{\mathrm{m}}$ & $\begin{array}{l}6.6 \\
7.9 \\
8.8 \\
9.8\end{array}$ & 10 \\
\hline $\mathrm{Fe}$ (III) (TPP) $\mathrm{Cl}$ & I $4 / \mathrm{m}$ & 13.534 & 13.534 & 9.820 & 90 & 90 & 90 & - & - & $5.06 \AA \mathrm{C}_{\mathrm{b}}-\mathrm{C}_{\mathrm{b}}$ & 9.82 & 9 \\
\hline
\end{tabular}




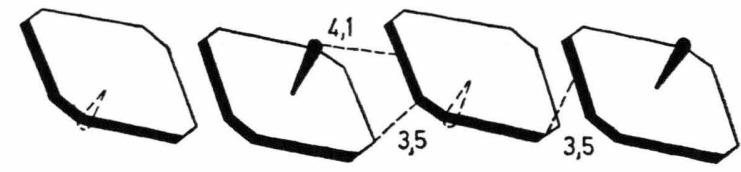

Fig. 5. Chain of nearest molecules of $\mathrm{Fe}$ (III) (OEP) $\mathrm{Cl}$ along the $a$-axis as seen from the $b$-axis.

In $\mathrm{Fe}$ (III) (TPP) Cl the molecules are stacked exactly along the $c$-axis so that interactions can pass over the chloride ligand as can be seen from Figure 6 . It can be noticed that not only the magnitude, but also the nature of the interaction is determined by the different geometrical arrangement of the molecules in these $\mathrm{Fe}$ (III) porphyrinchlorides.
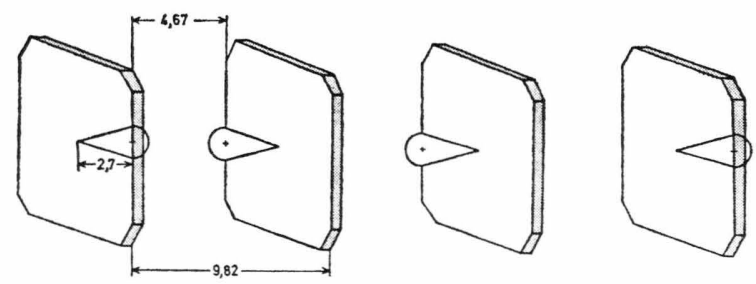

Fig. 6. Chain of nearest molecules of $\mathrm{Fe}$ (III) (TPP) $\mathrm{Cl}$ along the $c$-axis.

\section{Magnetic Susceptibility}

The results of our measurements of $\mathrm{Fe}$ (III) (OEC) $\mathrm{Cl}$ are given in Table 6. The data for $\mathrm{Fe}$ (III) (proto) $\mathrm{Cl}$ and $\mathrm{Fe}$ (III) (TPP) $\mathrm{Cl}$ have already been reported $^{11,12}$. In all three cases $\mu_{\mathrm{obs}}=2.828\left(\chi_{\mathrm{M}} T\right)^{0.5}$ is temperature independent down to $20 \mathrm{~K}$. For $\mathrm{Fe}(\mathrm{III})(\mathrm{OEP}) \mathrm{Cl}$, the average value of $\mu_{\mathrm{obs}}$ is $5.75(5) \mathrm{BM}$. Below $20 \mathrm{~K}$ the Curie-Weiss law $\chi_{\mathrm{M}}=$ $C /(T+\Theta)$ with $C=4.226$ and 4.619 and $\Theta=1.7$ and $3.1 \mathrm{~K}$ holds for $\mathrm{Fe}(\mathrm{III})(\mathrm{OEP}) \mathrm{Cl}$ and $\mathrm{Fe}(\mathrm{III})$ (proto) C.

Table 6. Magnetic susceptibilities and magnetic moment of $\mathrm{Fe}(\mathrm{OEP}) \mathrm{Cl}$ from 3.04 to $297 \mathrm{~K}$.

\begin{tabular}{lll}
$T$ & $\begin{array}{c}\chi_{\mathrm{M}} \times 10 \\
(\mathrm{Km})\end{array}$ & $\begin{array}{c}\left.\mu_{\mathrm{obs}} / \mathrm{mol}\right) \\
(\mathrm{B} . \mathrm{M} .)\end{array}$ \\
\hline 297 & 1.419 & 5.81 \\
160 & 2.609 & 5.78 \\
60 & 6.396 & 5.54 \\
38.0 & 11.005 & 5.78 \\
19.5 & 21.93 & 5.85 \\
9.3 & 40.37 & 5.48 \\
6.2 & 57.16 & 5.32 \\
4.3 & 70.27 & 4.92 \\
3.04 & 87.72 & 4.62 \\
\hline
\end{tabular}

The magnetic properties of iron(III) porphyrins may be approximately described by the Hamiltonian

$$
\begin{aligned}
\hat{\mathcal{H}}=\sum_{i}\{ & D\left[\hat{S}_{i z}^{2}-\frac{1}{3} S(\mathrm{~S}+1)\right] \\
& \left.+E\left(\hat{S}_{i x}^{2}-\hat{S}_{i y}^{2}\right)\right\}-\sum_{i j} 2 J_{i j} S_{i} S_{j} .
\end{aligned}
$$

This contains the crystal field splitting $D$ of the sextet ground term together with interactions between neighbouring spins. Neglecting the latter exchange term Griffith and Kotani ${ }^{13,14}$ derived an equation which qualitatively describes deviations from the Curie law.

At low temperatures $\mu_{\mathrm{obs}}$ falls more rapidly than predicted by this equation, if one introduces $D$. values as obtained from infrared and Mössbauer data [e.g. $\mathrm{Fe}$ (III) (proto) $\mathrm{Cl} D=6.8 \mathrm{~cm}^{-1} 15 \mathrm{Fe}$ (III) (OEP) Cl $\left.D=8.0 \mathrm{~cm}^{-1}\right]^{16}$.

Taking the intermolecular interactions into consideration further improves the fit to experimental data. To obtain an upper limit for the magnitude of the exchange integral $J$ we first consider only the nearest neighbor interactions and neglect the ligand field forces. Analysis of the crystal structure of $\mathrm{Fe}(\mathrm{III})(\mathrm{OEP}) \mathrm{Cl}$ and $\mathrm{Fe}$ (III) (proto) $\mathrm{Cl}$ reveals that the intermolecular interactions do not involve specific pairs of molecules, but rather chains. Magnetic moments of chains of paramagnetic centers are given by Earnshaw ${ }^{17}$. For a $\mu_{\text {obs }}=4.69 \mathrm{BM}$ at $4.48 \mathrm{~K}$ [ Fe(III) (proto) $\mathrm{Cl}]$, one obtains an exchange integral $\mathrm{J}=-0.22 \mathrm{~K}\left(-0.15 \mathrm{~cm}^{-1}\right)$ and for $\mu_{\mathrm{obs}}$ $=4.62 \mathrm{BM}$ at $3.04 \mathrm{~K}[\mathrm{Fe}(\mathrm{III})(\mathrm{OEP}) \mathrm{Cl}]$ and $J=$ $-0.15 \mathrm{~K}\left(-0.11 \mathrm{~cm}^{-1}\right)$ is given. The correct values are certainly smaller.

A more precise fit to the experimental data is obtained when the ligand field calculations are modified by the Heisenberg isotropic coupling between the $N$ spins of nearest neighbors in a linear chain. The susceptibility of a defined spin in an infinite chain has been calculated by Fischer ${ }^{18}$ :

$$
\chi_{\mathrm{M}}=\frac{N \beta^{2} g^{2}}{3 k T} \cdot S(S+1) \cdot(1+U) /(1-U)
$$

where

$$
U=\operatorname{coth}(2 J S(S+1) / k T)-k T / 2 J S(S+1) .
$$

Assuming that the susceptibility can be regarded as

$$
\chi_{\mathrm{M}}=\chi_{\mathrm{M} \text { crystal field }} \cdot f
$$

where

$$
f=(1+U) /(1-U)
$$




$$
\begin{aligned}
& \chi_{\mathrm{M} \text { crystal field }}=\frac{N \beta^{2} g^{2}}{3 k T} \\
& \cdot \frac{19+16 / x+(9-11 / x) e^{-2 x}+(25-5 / x) e^{-6 x}}{1+e^{-2 x}+e^{-6 x}}
\end{aligned}
$$

with

$$
x=D / k T
$$

and that $f$ affects both parallel and perpendicular susceptibilities equally, an antiferromagnetic coupling constant $J=-0.042 \mathrm{~cm}^{-1}$ [Fe(III) (proto) $\mathrm{Cl}]$ and $\mathrm{J}=-0.011 \mathrm{~cm}^{-1}[\mathrm{Fe}(\mathrm{III})(\mathrm{OEP}) \mathrm{Cl}]$ gives satisfactory agreement of the theoretical curve with the observed values as can be seen from Figure 7 . For $\mathrm{Fe}(\mathrm{III})(\mathrm{TPP}) \mathrm{Cl} J_{\|}=-0.28 \mathrm{~cm}^{-1}$ and $J_{\perp}=$ $+0.11 \mathrm{~cm}^{-1}$ are found ${ }^{19}$ giving an average value of $J=-0.022 \mathrm{~cm}^{-1}$.

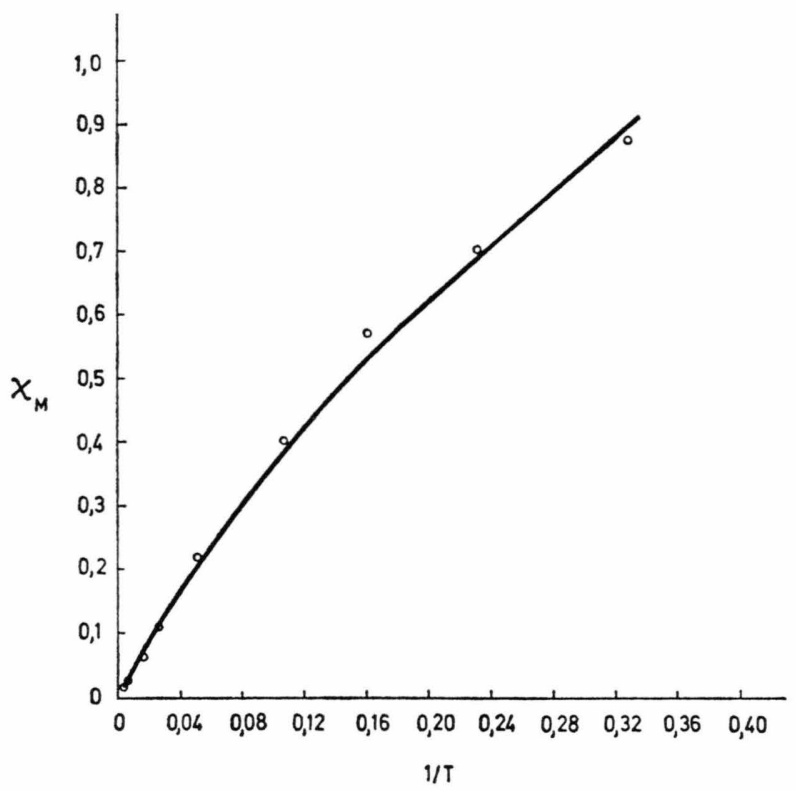

Fig. 7. Comparison of experimental susceptibility per mole (dots) and theoretical curve for Fe(III) (OEP) Cl.

\section{Discussion}

The crystal structure of the iron(III) porphyrins reveals that intermolecular interactions in $\mathrm{Fe}$ (III) (proto) $\mathrm{Cl}$ and $\mathrm{Fe}(\mathrm{III})(\mathrm{OEP}) \mathrm{Cl}$ do not involve specific pairs of molecules, but rather chains. The arrangement of molecules in $\mathrm{Fe}(\mathrm{III})$ (proto) $\mathrm{Cl}$ is closer and more complicated than in $\mathrm{Fe}$ (III) (OEP) Cl. This is reflected in the EPR spectra of Fe(III) (proto) $\mathrm{Cl}$ for which the largest linewidths are ob- served. For a cluster of spins a general spin Hamiltonian can be written as follows ${ }^{20}$ :

$$
\hat{\mathcal{H}}=\sum_{i} \hat{\mathcal{H}}_{i}+\sum_{i \neq j} \hat{\mathcal{H}}_{i, j} .
$$

$\hat{\mathcal{H}}_{i}$ is the spin Hamiltonian for the isolated spin system and $\hat{\mathcal{H}}_{i, j}$ represents the interactions between the spins.

$$
\begin{aligned}
& \hat{\mathcal{H}}_{i}=\beta \hat{B} g \hat{S_{i}}+\hat{S}_{i} \cdot D \cdot \hat{S}_{i}, \\
& \hat{\mathcal{H}}_{i j}=J_{i j} \hat{S^{\prime}} \cdot \hat{S_{j}}+D_{i j}^{\mathrm{E} x}\left(3 \hat{S}_{Z i} \hat{S_{Z j}}-\hat{S_{i}} \hat{S_{j}}\right) \\
& \quad+E_{i j}^{\mathrm{E} x}\left(\hat{S}_{x i} \hat{S}_{x j}-\hat{S}_{y i} \hat{S}_{y j}\right) .
\end{aligned}
$$

The terms in $\mathcal{H}_{i}$ have their usual meaning. $J_{i j}$ is the isotropic exchange between a pair of spins; $D^{\mathrm{Ex}}$ and $E^{\mathrm{Ex}}$ represent the anisotropic exchange and dipolar contributions. The above Hamiltonian is too complicated and we have resorted to drastic simplifications in order to explain just the trends in the EPR spectra. We have considered the interaction between only three $\mathrm{Fe}$ atoms in a chain and assumed that the isolated $\mathrm{Fe}(\mathrm{III})$ porphyrin molecules can be represented by the effective spin Hamiltonian $\left(S^{\prime}=1 / 2\right)$

$$
\mathcal{H}_{i}=\beta\left[g_{\|} B_{Z} S_{Z}+g_{\perp}\left(B_{x} S_{x}+B_{y} S_{y}\right)\right]
$$

where

$$
g_{\|}=2.0, \quad g_{\perp}=6.0 .
$$

If we also assume that the zero field splitting in the isolated $\mathrm{Fe}$ (III) complexes is much larger than the quantities $D^{\text {Exc }}$ and $E^{\text {Exc }}$, we can write the spin Hamiltonian for the three interacting hemes as folfows,

$$
\begin{aligned}
\mathcal{H} & =\beta\left[g_{\|} B_{Z} \hat{S}_{Z}+g_{\perp}\left(B_{x} \hat{S}_{x}+B_{y} \hat{S}_{y}\right)\right] \\
& +D\left[S_{Z}-\frac{1}{3} \hat{S}(\hat{S}+1)\right]+E\left(\hat{S}_{\mathrm{x}}^{2}-\hat{S}_{\mathrm{y}}^{2}\right) \\
& +J\left(\hat{S}_{1} \cdot \hat{S}_{2}+\hat{S}_{2} \cdot \hat{S}_{3}+\hat{S}_{3} \cdot \hat{S}_{1}\right) ;
\end{aligned}
$$

where $D^{E \mathrm{x}}$ and $E^{\mathrm{Ex}}$ are replaced by $\mathrm{D}$ and $E$, since these are the only spin-spin interactions occuring explicitly in the Hamiltonian. We have also assumed complete equivalence of the three iron(III) porphyrins as well as parallel $g$ and $D$ tensors. The cluster is treated as an effective $S=3 / 2$ system with $J \ll h v$, where $h v$ is the microwave quantum. The above Hamiltonian was diagonalized ${ }^{21}$ exactly for values of $D \gg h v, D \ll h v$ and $D=h v$. For $D \ll h v$ the lines at $g=6$ and $g=2$ are split to a small extent. One gets three closely spaced lines (separation $=100$ Gauss at $v=9.3 \mathrm{GHz}$ ) in the $g=6$ and $g=2$ region. For $D=h v, E=0, g_{\perp}$ transitions occur 
around 3.5 and also at very low fields $g>8$. But one also gets transitions at $g=2$ which are not observed experimentally in the case of $\mathrm{Fe}$ (III) (OEP) $\mathrm{Cl}$. The above calculation is certainly not meant to predict the complete spectrum. It is only to show that $g=3.5$ lines can arise from intermolecular spinspin interactions.

A quantitative interpretation of the EPR data will have to take into acount the complete symmetry of the cluster and all the isotropic and anisotropic interactions. Bulk magnetic susceptibility properties, on the other hand, are well accounted for by the equations given in Section II,C. Only the influence of the crystal field and the Heisenberg isotropic exchange coupling are needed to be considered.

\section{Conclusion}

Crystal data of $\mathrm{Fe}(\mathrm{III})$ porphyrin chlorides demonstrate that the paramagnetic metal ions are

1 M. Weissbluth, "Hemoglobin", Molecular Biology, Biochemistry and Biophysics, Vol. 15, Springer-Verlag, Berlin 1974.

2 J. S. Griffith, Proc. Roy. Soc. London, A 235, 23 [1956].

3 J. Peisach, W. E. Blumberg, and A. Adler, Ann. N. Y. Acad. Sci. 206, 310 [1973].

4 W. E. Blumberg and J. Peisach, Magnetic Resonance in Biological Research, ed. by C. Franconi, Gordon \& Breach, New York 1971, p. 67.

5 J.-H. Fuhrhop and K. Smith, Porphyrins and Metalloporphyrins, ed. K. M. Smith, Elsevier, Amsterdam 1975, p. $804 \mathrm{St}$.

6 G. M. Sheldrick, SHELX-Program for Crystal Structure Determination, Cambridge 1975.

7 D. T. Cromer and J. T. Waber, Acta Cryst. 18, 104 [1965].

8 D. T. Cromer and D. Libermann, J. Chem. Phys. 53, 1891 [1970].

9 J. L. Hoard, G. H. Cohen, and M. D. Glick, J. Amer. Chem. Soc. 89, 1992 [1967].

10 D. F. Koenig, Acta Cryst. 18, 663 [1965].

11 S. Sullivan, P. Hambright, B. J. Evans, A. Thorpe, and J. A. Weaver, Arch. Biochem. Biophys. 137, 51 [1970]. separated by more than $6.6 \AA$. Direct magnetic coupling should therefore be negligible.

The interactions observed in the EPR spectra probably occur through the $\pi$-systems of the porphyrin ligands as well as the axial ligands. Such "superexchange interactions" are apparently easily affected by the crystal packing mode. Similar results have also been found in related systems like Mn(II) phthalocyanine ${ }^{22}$, iron (III) bis (dithiocarbamat) ${ }^{23}$ and $\mathrm{Co}$ (II) (TPP) ${ }^{24}$.

\section{Acknowledgement}

We thank W. S. Sheldrick and A. Borkenstein for their assistance in crystallographic part of this work and Mr. Felton for magnetic susceptibility measurements. The crystallographic calculations were carried out with the program SHELX (G. M. Sheldrick) and auxiliary programs written by W. S. Sheldrick.

12 C. Maricondi, W. Swift, and D. K. Straub, J. Amer. Chem. Soc.91, 5205 [1969].

13 M. Kotani, Progr. Theor. Phys. Supp. 17, 4 [1961].

14 J. S. Griffith, Biopolymers 1, 35 [1964].

15 P. L. Richards, W. S. Caughey, H. Eberspraecher, G. Feher, and M. Malley, J. Chem. Phys. 47, 1187 [1967].

16 B. W. Fitzsimmons, J. R. Sams, and T. B. Tsin, Chem. Phys. Letters 38, 588 [1976].

17 A. Earnshaw, B. N. Figgis, and J. Lewis, J. Chem. Soc. (A) 1966, 1656 .

18 M. E. Fischer, Amer. J. Phys. 32, 343 [1964].

19 G. L. Neiheisel, J. L. Imes, and W. P. Pratt, Jr., Phys. Rev. Letters 35, 101 [1975].

20 J. Owen and E. A. Harris, in Electron Paramagnetic Resonance, ed. by S. Geschwind, Plenum Press, London 1972, p. 427.

21 QCPE program no. 133 by H. M. Gladney and J. D. Swalen, QCPE catalog no. X, 1974.

22 C. G. Barraclough, A. K. Greyson, and S. Mitra, J. Chem. Phys. 60, 962 [1974].

23 G. E. Chapps, S. W. McCann, H. H. Wickmann, and R. C. Sherwood, J. Chem. Phys. 60, 990 [1974].

24 M. Sato, H. Kon, H. Akoh, A. Tasaki, C. Kabuto, and J. V. Silverton, Chem. Phys. 16, 405 [1976]. 